Illinois State University

ISU ReD: Research and eData

Theses and Dissertations

3-22-2015

\title{
Watch And Learn: A Documentary Exploring The Effects Of Video- Based Pedagogy
}

Chris Matthew Noel

Illinois State University, christophermnoel@hotmail.com

Follow this and additional works at: https://ir.library.illinoisstate.edu/etd

Part of the Communication Commons, Curriculum and Instruction Commons, and the Educational Methods Commons

\section{Recommended Citation}

Noel, Chris Matthew, "Watch And Learn: A Documentary Exploring The Effects Of Video-Based Pedagogy" (2015). Theses and Dissertations. 368.

https://ir.library.illinoisstate.edu/etd/368

This Thesis is brought to you for free and open access by ISU ReD: Research and eData. It has been accepted for inclusion in Theses and Dissertations by an authorized administrator of ISU ReD: Research and eData. For more information, please contact ISUReD@ilstu.edu. 


\title{
WATCH AND LEARN: A DOCUMENTARY EXPLORING THE EFFECTS OF VIDEO-BASED PEDAGOGY
}

\author{
Christopher M. Noel
}

38 Pages

May 2015

This 20-minute film explores the use of hybrid lesson plans, those consisting of traditional in-class teaching and interactive video outside of the classroom. Using six voluntary Graduate Teaching Assistants as participants, the documentary follows the participants as they give their ideologies on teaching, perform either a traditional lesson plan or the hybrid lesson plan, and participate in a focus group to give their opinion on the perceived benefits or drawbacks of having hybrid lesson plans in the classroom. 
WATCH AND LEARN: A DOCUMENTARY EXPLORING

THE EFFECTS OF VIDEO-BASED PEDAGOGY

CHRISTOPHER M. NOEL

A Thesis Submitted in Partial Fulfillment of the Requirements for the Degree of

MASTER OF SCIENCE

School of Communication

ILLINOIS STATE UNIVERSITY

2015 
(C) 2015 Christopher M. Noel 


\section{WATCH AND LEARN: A DOCUMENTARY EXPLORING THE EFFECTS OF VIDEO-BASED PEDAGOGY}

CHRISTOPHER M. NOEL

COMMITTEE MEMBERS:

Maria A. Moore, Chair

John R. Baldwin

Brent K. Simonds 


\section{ACKNOWLEDGMENTS}

The writer wishes to thank his committee members, Juan Saliba, Chad Woolard, Dr. Cheri Simonds, Julie Maio, Eric Varney, Kody Frey, Emily Reardon, Linda Noel, Alexander Oliver, Carly Schrimpl, everyone at Health and Wellness, and all of those who helped make the videos that made this thesis possible.

C.N 


\section{CONTENTS}

Page

ACKNOWLEDGMENTS $\quad$ i

CONTENTS

CHAPTER

I. ONE PAGE SUMMARY 1

II. TREATMENT 4

$\begin{array}{lll}\text { III. FUNDING } & 8\end{array}$

IV. REVIEW OF RELATED LITERATURE 9

The Bystander Effect 9

The Bystander Effect in Demographics $\quad 15$

Empathy 17

Video-based Education $\quad 22$

Research Questions $\quad 25$

$\begin{array}{ll}\text { REFERENCES } & 27\end{array}$

APPENDIX: Hybrid Lesson Plan Used by Participants 32 


\section{CHAPTER I}

\section{ONE PAGE SUMMARY}

The researchers will use previous video to conduct research using six participants for this documentary. In total, there are four videos. Three of the videos are scenarios that depict alcohol poisoning, a withdrawn individual, and consent to sexual contact when intoxicated and how to become an active bystander, or how to intervene in these situations. The fourth video is predominately slides with some video and voice-over. The fourth video gives strategies on how to become an active bystander. A lesson plan created utilizing the videos will be used in this documentary project.

The videos will be used in the Communication as Critical Inquiry (COM 110) course. COM 110 is a requirement for all students enrolled at Illinois State University, which teaches a variety of topics including civic engagement, some theory, and group dynamics as well as group roles. The teaching program in the School of Communication Graduate Teaching Assistantship is ranked one of the best in the nation for its comprehensive tutelage of incoming instructors. Six second-year graduate students will be chosen using criterion and typical-case sampling. These students will be in their fourth semester of teaching COM 110 and have had experience in the previous iteration of the course lessons. 
The selected voluntary participants will be interviewed on-camera prior to the lesson. Questions seek the participants' perceptions of teaching, previous experience with a good or poor instructor, thoughts of using video in the classroom, and their own philosophy of teaching in the standard classroom environment. Post-interview, three instructors will use their original lesson plan and content to teach the course as they have in previous semesters.

The three instructors selected to use the hybrid format will teach a two-day lesson plan. The instructor will give a brief overview of the genesis of the bystander effect and its meaning. They will then assign the four videos as well as three 4-question, short answer sheets that are based on the content in the scenarios. Students will complete the worksheets outside of class using the videos for a combined time of roughly 30 minutes.

During the following class period, instructors will pose questions that will facilitate a discussion that connects content from the videos with content from the course such as: decision making, citizenship, groupthink, and perceptions. During this two-day lesson, observational video will be shot of the instructor teaching said lesson. This video will be synthesized with additional B-roll.

Post-lesson, the instructors will be part of a focus group, in which they will be filmed answering questions about their thoughts of how the lessons went. The focus group portion of the documentary will be crucial to understand how hybrid lessons affect the learning environment. The focus group will have a juxtaposed discussion between the traditional lessons and the hybrid lessons. Information gathered will then be edited and 
constructed at the end for the purpose of viewing the content in a linear, documentary fashion. This documentary has received IRB approval. 


\section{CHAPTER II}

\section{TREATMENT}

This documentary film will run about 20 minutes. The initial purpose of the study is to see how one can combine the concepts presented by Health and Wellness that delineate how to become an active bystander with those of a traditional Communication as Critical Inquiry classroom environment. The synthesized product became four videos that present information and scenarios that represents key concepts from Health and Wellness's program and incorporates concepts from COM 110. The product is one overall lesson plan utilizing the videos that will be taught to COM 110 students alongside traditional lesson plans, which is the focus of this documentary.

In 1964, Kitty Genovese was sexually assaulted and murdered in Queens, New York, while 38 individuals witnessed it, and yet none of them helped (Manning, Levine, \& Collins, 2007). This was the beginning of what would become known as the bystander effect. In the present study, the video opens with a brief dramatic reenactment of this. It is very stylized and film-esque. Afterwards, the camera pulls back and we see a student sitting in a seat while the projector flickers with the story on screen. This student is the focus of the sub-narrative that connects the portions of main story, which are the preinterview, lesson, and focus group.

Six individuals that meet the criterion and typical-case samplings by being a second-year Graduate Teaching Assistant in the School of Communication teaching 
COM 110 for at least the fourth semester in a row will be the focus of the main story as we learn about their experience, methodology, and central meaning of teaching. This connects with the audience in the beginning as we hear what the individuals enjoyed as students from their classes and how it affects their current teaching. The focus will then shift to the basis of the study as, once again, the student watches the videos used in the study. There are brief portions of the video when the narrator explains their importance. The video zooms in on the screen and fades away as we see our subjects teaching. The narrator explains who is using the different lesson plans and delineates how they differ. The audience is able to see segments used and how they differ from one another in teaching styles.

After the two-day in-class footage of a brief explanation of the bystander effect and the assigning of the videos and worksheets, we go back to the student who walks along the Illinois State University quad. The individual is contemplative as the narrator explains the effectiveness of video in the generation of knowledge. We begin to see how the knowledge of information used in the classroom setting with video outside of the classroom has made the individual begin to contemplate concepts, which they had never thought about.

We fade in to the focus group. This portion is used to answer the research questions but remains relatively unfiltered, with honest responses to the lesson plans and thoughts on this new form of classroom instruction. The denouement of the film consists of an over-the-shoulder shot of the student as the narrator summates the study and the comments of the instructors. It is dark outside and this is where we see the student come 
across someone in distress and the camera zooms in on the student's face as if they are deciding whether or not to act. The screen fades to black.

The style used in this documentary is a conglomeration of the Netflix original documentary Printing the Legend and the film ... and the Pursuit of Happiness. The style also combines the narrative structures such as Mysteries at the Museum. This is an appropriate way to immediately give evidence information about the topic of hybrid lesson plan effectiveness while also to have entertainment value using a scripted, enacted, connective narrative. The modern documentary integrates more than the simple capture of footage and splicing it together; it is a strong, dramatic narrative. Matthews et al. (2001) found that individuals are more receptive to a message when it occurs in social or cultural environments that are similar to their own. This fictionalized narrative will be most effective as it will resonate with those in academia, be they students or instructors. This is why the specific demographic for this study are tailored for those in academia.

Though there have been documentaries about learning through video, there has never been one quite like the study proposed. One study does come close to the proposed concept, which was done by Cherrett, Willis, Price, Maynard, and Drior (2009). The authors found using a training video in opposition to traditional, in-class instruction that, while many found the interactive training video to be impactful, the most effective use was interactive video combined with traditional, in-class instruction. This differs from the current study by the nature of instructional video compared to integrated lesson plan, but it draws on an old finding to navigate a hopefully effective new finding. This project will present an integrated lesson plan to base on a traditional lesson plan of a course book. It 
differs from previous works to integrate with real world concepts of prosocial behavior with those of the course book in a way that should be digestible to the viewer. This documentary seeks the answer to the question: Do instructors believe this form of hybrid learning surpasses traditional course lesson 


\section{CHAPTER III}

\section{FUNDING}

The camera and equipment being used belong to the School of Communication. This includes an HD video camera, a boom microphone, a lavaliere microphone, and charging equipment. The director of this documentary also has an additional camera, which will be used throughout. All individuals appearing within are volunteers and receive no reimbursement for their participation in the film. This film will not only be shot with equipment from the School of Communication at Illinois State University, but it will also be shot predominantly at Illinois State University, which reduces the cost of the travel as all participants will be on campus when they are interviewed or filmed. The actors will be filmed on location. This includes a gas budget, which is solely setup and used by the director.

Schedule

Begin Filming B-roll: 1/20/15

Find Participants: 2/14/15

Film B-roll of Participants: 2/14/15- 3/10/15

Finish B-roll: 2/28/15

Film Lesson: TBD (Mid-March)

Film Focus Group: 3/18/15 


\section{CHAPTER IV \\ REVIEW OF RELATED LITERATURE \\ The Bystander Effect}

To understand the bystander effect, it is advantageous to look at the genesis of the concept in regards to the case of Kitty Genovese. Kitty Genovese was a young woman who was sexually assaulted and murdered outside her apartment in the early morning hours of March 13, 1964 in Queens, New York (Manning, Levine, \& Collins, 2007). During this time, 38 individuals were witness to the event, and yet none of them called the police nor came to the aid of the 28-year-old woman (Manning et al., 2007). Manning, Levine, and Collins (2007) contend that the story of Kitty Genovese is a modern parable of large groups and how they are an active or passive threat because, they found, large groups lack rationality.

Five years after the Genovese incident, Turner (1969) released an article with a framework created around the presidential address in the same year that became the leading article that would later be associated with the bystander effect. Turner (1969) found that third parties only become concerned when they identify with one of the parties. The bystander only tends to take action if she or he identifies with a victim or has an interest in the conflict (Turner, 1969). The authors also found that individuals align themselves with the party that is similar in interests, more rewarding, with whom they have contact, and also with whom they are familiar. In an early study of the phenomenon, 
Latane and Rodin (1969) found that, among 125 male undergraduates, individuals that were witness to a confederate woman falling were more likely to help if they were not in a group. Individuals that were in combined or multiple individual groups were less likely to exhibit helping behaviors. In the present day, studies like that by Katz, Olin, Herman, and DuBois (2013) found that individuals are more receptive to bystanderoriented material, such as posters against sexual violence, and that "exposure to the posters was associated with greater willingness to help others" (p. 527). This leads to a greater body of research, which begins to delineate the parameters of what effects the individual in bystander situations.

The bystander effect is made up of certain criteria, for which Chekroun and Brauer (2002) sought to find a correlation. The authors conducted a three-tier study to evaluate whether or not personal implication was a factor in regards to whether someone would intervene in a social situation where individuals deviated from norms. The authors used confederates to either spray graffiti on an elevator in a shopping mall or throw an empty water bottle into a bush in a small neighborhood park to demonstrate deviant acts. The authors found that perceived deviance was considered the same in both instances and concluded that social control behavior is determined by the perceived deviance witnessed. Individuals in small groups with frequent face-to-face contact use positive and negative solutions to perpetuate social norms, whereas large, unstructured social groups tend to perpetuate social norms solely through negative sanctions. This means that individuals who violate commonly accepted social norms in a common area used by those individuals around them, who maintain the social norms in places such as a public park or public shopping mall, are placed in check. 
There were two other studies that echoed the concept of implication as reasoning for intervention. The first was a two-part study that simulated the features of the 'good Samaritan' experiment during a soccer game when they had confederates pose as fans who begin to beat a fan of the opposing team (Levine, Prosser, Evans, \& Reicher, 2005). The authors found that intervention was highest when the bystander is able to identify with the victim. Individuals within the in-group were more likely to be helped by the bystander; however, both fan sets were likely to intervene because they could identify, not with the team if on the opposing side, but because of identification with the fan as a fellow supporter of the sport (Levine et al., 2005). Similarly, Brauer and Chekroun (2005) found that individuals were more likely to exert social control if their self-interests were at stake. Individuals were more likely to illicit social control and act when they felt implicated by the transgression upon places or objects held important by the norms of the community with which they aligned themselves. This concept of implication and identification is also shown by Bennett, Banyard, and Garnhart's (2014) study, in which participants felt a "sense of responsibility and feeling that the situation is interventionappropriate as the primary variable that make it more likely they will step in" (p. 491). Banyard (2008) found that individuals exhibited more prosocial bystander behaviors when they had greater knowledge of sexual violence, which he connects to the ability of the individual to recognize "the problem of sexual violence and [the ability] to identify the situation as risky or problematic, an important component of bystander engagement" (p. 94

Although implication by identification caused proactive behaviors, there are several factors that hinder individuals' ability or will to intervene. Brauer and Chekroun 
(2005) found that individuals may not get involved because they wanted to avoid the conflict or did not have the "guts" to intervene. Thornberg (2007) conducted a qualitative case study with 11 elementary school students and examined their reasoning behind lack of helping behavior in situations where their fellow students were in distress. The author explained seven concepts that contributed to bystander behavior: trivialization, dissociation, embarrassment association, busy working priority, compliance to a competitive norm, audience modeling, and responsibility transfer. The author also found that students deferred responsibility to the teacher and constructed different definitions of the emergency situation that they were unskilled and that empathy was a major factor. Prosocial behavior itself is a large part of individuals deciding whether or not to get involved in a bystander event (Machackova, Dedkova, Sevcikova, \& Cerna, 2012).

There are certain inhibitory factors that occur when bystanders witness behaviors that go against standardized norms in social settings (Chaurand \& Brauer, 2008). Chaurand and Brauer (2008) developed three factors, which were indicators whether an individual was likely to become an active bystander: responsibility, legitimacy, and hostile emotions. This means that individuals who take social control responsibility, feel legitimately empowered, and have emotions such as anger and disdain are more likely to become active bystanders than those that do not meet the specific criteria (Chaurand \& Brauer, 2008). Although the individual may or may not be inhibited by aforementioned instances of implication and the three factors found by Chaurand and Brauer, there is also support in the concept of the "positive bystander effect" (Fischer \& Greitemeyer, 2013). Fischer and Greitemeyer (2013) present evidence that, in instances where there were highly probable levels of negative consequence or danger, it was beneficial to have 
passive bystanders nearby. They found that individuals who came across "fierce" confederate were more likely to say something if there were passive bystanders nearby that could potentially provide physical and social support if needed. This leads one to assume that individuals would be more likely to intervene in a situation where, if they needed assistance, the passive bystanders may intervene as well.

Criteria are not the only factors that can help or hinder reaction by bystanders. Garcia, Weaver, Moskowitz, and Darley (2002) found the perception of others around the individual during times of engagement for a bystander event hindered the active role the person would usually take. Over five studies, they found that individuals that perceived others around them in the first instance were less likely to exhibit helping behavior in the second instance. The presence of a perceived other in these circumstances also resulted in the participants responding quicker with words like "unaccountable", which becomes a central ideology about the implicit bystander effect, which delineates the lack of responsibility-taking by individuals that perceive others will intervene in the given scenarios (Garcia et al., 2002). One could conclude an individual may not take responsibility even if they think someone may intervene; they would not have to see someone in sight to feel this way.

This is not to be completely damning of the current generation and perception of helping behaviors. Howard, Nelson, and Sleigh (2011) surveyed 95 undergraduate students who received either one of three priming conditions or a control condition, which was without prime. Each priming condition had the participant write about a given topic. The first condition pertained to giving help, the second condition referred to 
receiving help, and the final condition referred to being denied help. The study indicated that young adults are likely to believe that individuals act selflessly (Howard et al., 2011). The study's priming was not a factor, and the authors contend "participants' beliefs and behaviors tied to altruism may be stable tendencies that are not easily influenced by brief interventions" (Howard et al., 2011, p. 172). These two studies confirm that although beliefs may affect ones' decision making, individuals' prior experiences or mindset on purely selfless acts is also an indication on exhibition of helping behavior (Garcia et al., 2002; Howard et al., 2011).

Bennett, Banyard, and Garnhart (2014) also looked at ways that the bystander effect can be facilitated or inhibited. They surveyed 242 first-year college students twice over the course of their first semester. The surveys used multiple scales measuring prosocial behavior, depression the individual had exhibited in the previous week, optimism, support given by others in the previous month, sense of community, degree of control over their life, barriers to the bystander intervention, and helping behaviors in an instance of sexual violence (Bennett et al., 2014). The authors contend that individuals

who have high prosocial tendencies usually reported less barriers to keep them from acting in a bystander intervention. Individuals are also more likely to take action when they know the victim (Bennett et al., 2014). Another type of barrier is the fear of negative evaluation, which, in high levels, inhibits the individual from performing a helping act when there is no audience to the act itself (Karakashian, Walter, Christopher, \& Lucas, 2006). Relationship or prior knowledge of the individual is also an inhibitory element in the bystander intervention process as individuals showed more supportive behavior if 
they had had a good relationship with the individual prior to the event as opposed to individuals that had a poor, or nonexistent relationship with the individual (Machackova et al., 2012).

\section{The Bystander Effect in Demographics}

The bystander effect phenomenon is prevalent in schools (Hudson \& Bruckman, 2004). Hudson and Bruckman (2004) found four mechanisms that contribute to bystander behavior: self-awareness, social cues, blocking, and diffuse responsibility. They looked at behavior exhibited by Christian and Sara where one, Sara, was shy and the other, Christian, was more confident and came from a French speaking country. They found that higher levels of self-awareness were productive for high-confidence individuals and counter-productive for low-confidence individuals. In the workforce, bystander action is also a useful tool. Scully and Rowe (2009) contend that bystander training in the workplace encourages positive actions by using prosocial responses to individuals' positive social actions. Bystanders in the workplace can also be beneficial in solving conflicts. Using scenarios would enable individuals to experience bystander intervention

while also bringing them more confidence to use said actions (Scully \& Rowe, 2009). They found that bystander intervention in the workplace fosters inclusion by positive reinforcement of positive social normative execution.

Foubert (2013) surveyed 250 undergraduate and graduate students using the Religious Orientation Scale, the Bystander Efficacy Scale, the Bystander Willingness to Help Scale, the Exposure to Internet Pornography Scale, and a brief demographic questionnaire. The author found that individuals that had motives such as keeping faith 
central in their lives and studying the Bible were less likely to view pornography and more likely to intervene in a sexual assault situation. This study alludes to the finding that moral stringent beliefs are more likely to make an individual become an active bystander.

The bystander effect is also influenced by things like kinship, which makes taking action salient to the bystander because of the attached relationship with the victim or individual in need (Fredricks, Ramsey, \& Hornett, 2011). The effect can also occur in specific settings and among specific groups as Fledderjohann and Johnson (2012) found. Prosocial behavior intervention was found to be effected by how frequently the person witnessed neglect and their perception of the event, the community they live in, their age, education, and gender. They surveyed 50 communities in the Midwest presenting 3,679 respondents. They found that women were $30 \%$ more likely than men to observe neglect of a child than men. Nearly half of all subjects took no action when watching an act of neglect towards a child (Fledderjohann \& Johnson, 2012). They discovered individuals that were widowed, had checked "other" as employment as opposed to full-time, had higher education, or reported community comfort and cohesion were more likely to take action.

Masculinity becomes an inhibitor of prosocial actions (Carlson, 2009). Carlson (2009) interviewed 20 participants of college men aged between 18 and 19 that were interviewed in a qualitative study where they were given three scenarios. The first scenario placed the individual walking home and witnessing three men attacking another man, the second scenario had the participant witnessing a man hitting a woman, and the final scenario took place at a party where the participant walked in on a woman be gang- 
raped while she was obviously unconscious. The author found that most of the individuals indicated that they did not want to look weak in the presence of other men and they would not intervene in first scenario because the victim may have deserved it or asked for it. The author found there were also themes such as men must not cry, must be big and powerful, fight, be conscious of their physical stature, protect women, engage in heavy drinking, and think that they are different from their peers; however, the dominant theme was that men must not or show weakness. The participants felt that aggression was a large part of being male and the first two scenarios were dependent on the context. They generally chose to use active involvement in the scenarios. The responses to the protection of women were contradictory to the initial response when participants identified with the bystanders in the gang-rape scenario and males must assert their heterosexuality in instances where they intervene in a sexual act. The author contends that empathy, a major factor in bystander intervention, is seen as a "feminine" characteristic and individuals are likely to second guess intervening.

\section{Empathy}

Empathy is a cognitive and affective process (Bailey, Henry, \& Von Hippel, 2008). It has been defined as "a phylogenetically continuous ability based in group living and extended care-giving that has been extended through the extension of cognitive abilities to be applicable to non-kin and beyond the scope of one's own experience" (de Waal, 1996, p. 33). Empathy is a process where perception precedes action and that is able to cause a chaining event by others that witness the action as they witness the event or by the empathic individual as he or she feels what another feels, known as emotional 
contagion (de Waal, 1996). The author contends that empathy can, theoretically, be a learned condition, but it is a prefrontal activity. However, as individuals age, they tend to show less cognitive empathy: They begin distancing themselves from social activities, and the ability for them to understand others' mental states lessens. This change could be due to the lack of mobility or declining health of the individual. It may be possible that the individual is unable to empathize with another because the individual has had an injury or their mental capacity has diminished enough to limit prefrontal activity (Bailey et al., 2008). This finding echoes Piff et al. (2010) who suggest these individuals begin distancing themselves from other social groups, or exhibiting antisocial behavior, which is the antithesis of prosocial behavior, which breeds empathy.

Morality can be associated with individuals' empathic ability. Nwanko (2013) found that some teachers had moral judgment that was essential, believed what is good for the individual is good for the group, and that moral judgment was significantly related to the level of emotional empathy. This means that the higher the individuals' emotional empathic ability, the higher the individuals' moral judgment. Empathic ability is also found in a different structured setting like that of a courtroom. Wood, James, and Ciardha (2013) found in a courtroom setting, individuals with high levels of empathy were found to have less stringent views on the defendant's responsibility for the crime. The authors also found that even when the defendant showed no remorse, individuals with higher levels of empathy perceived the individual to be remorseful (Wood et al., 2013). The judgment of individuals by highly empathic individuals harkens back to the idea that the 
more we are around people, the more we are able to relate them, then the more likely we are to care about the well-being of the individuals whom we judge.

Cooperation with others is a prosocial behavior and prosocial behavior is, once again, an essential part of the process of empathy. Xu, Kuo, and Zhong (2012) found that individuals were more likely to forgive their partners if they had high levels of empathy, even after finding out their partners' defection. The authors also found that individuals with high levels of empathy had a "returning-good-for-evil" mentality, or, being able to do positive actions even after their partner had done negative actions in the study. The authors found no gender difference in the decision making process of cooperation or deflection; however, they found that men tended to show more positive reactions to their partner than females. Women were more likely to self-report that they would have positive reactions and feelings towards those that defected. It could then be inferred that women are less likely than men to empathize with their defector, however, this study was done in China and, as the authors say, "Males' higher level of behavioral forgiveness in Study 2 might be due to the cultural expectation of magnanimous men" (p. 113). Thus

males' ability to empathize and forgive their defector could be a strictly cultural phenomenon.

Though individuals may be able to empathize with their offender's defection, there are different circumstances when it comes to helping others in distress. Batson, Fultz, and Schoenrade (1998) found a difference when helping others between egoistic motivation and empathic motivation, which is predominantly an altruistic act. They found that if motivation by empathy is directed towards the egoistic goal of reducing the 
emotion, then one is able to alleviate it by either helping or escaping the situation, whereas those that seek an altruistic goal must help in the situation to alleviate the emotion. The authors also contend that someone who generally has an egoistic motivation wants to escape the awareness of the other individual's suffering, which can go hand-in-hand with physical removal from the situation. This form of escape would actually be detrimental for individuals that reported high levels of empathy because they would not be able to satiate the need to help the individual through their altruistic motivation. This type of motivation is to achieve the desired avoidance of either social or self-punishment.

Empathic individuals try to help others that are distressed; however, they also receive images that they interpret and that resonate with their empathic nature. Two hundred and sixty students viewed 12 antismoking ads, which contained fear, empathy, or were neutral of both fear and empathy. Individuals that were seen as having high levels of empathy experienced positive direct and positive indirect effects after watching fearinducing antismoking advertisements (Shen, 2011). However, results found that empathyarousing messages tended to be more persuasive to audiences than those that aroused fear (Shen, 2011). This could be due to what has been shown in previous literature about the effectiveness of prosocial behavior in individuals and the levels of empathy. Individuals that are prosocial tend to be more likely to help someone in distress, and advertisements that present an individual in distress would be more effective because of the empathic nature of the individuals and the want to motivate change in an illness. Empathy is a prosocial exhibition in regards to others and individuals that experience this prosocial 
behavior are more likely to recognize individuals' distressed facial expressions, such as fear, as opposed to those that show lower instances of experienced states of prosocial behavior (Marsh, Kozak, \& Ambady, 2007). These individuals are better able to recognize distress by having higher levels of empathy and would be more prone to act in a helping manner.

Karniol, Gabay, Ochion, and Harari (1998) found that although femininity and empathy were positively correlated, masculinity was not. They also found that later in adolescence boys become more feminine but still retain masculinity, however, masculinity has no correlation with empathy itself. This study shows that empathy is not acted upon by gender, or sex, but by gender-orientation.

This empathic nature is also related to socioeconomic status. Piff, Kraus, Cheng, Cote and Keltner (2010) found that individuals with lower socioeconomic status "behave in a more prosocial fashion" (p. 774) than those in a higher socioeconomic status. They found that individuals of low socioeconomic status were more generous and gave more of their earnings to charities than those in high socioeconomic statuses (Piff, et al., 2010).

There are myriad effects that empathy have on decision-making which included more generosity, support for charity, trusting behavior towards strangers, and helping behavior towards individuals in need which cumulates to behaviors that increase another's welfare as opposed to those in lower socioeconomic statuses (Piff et al., 2010). The authors speculated that individuals showed more generosity and general empathic concern for others due to their heightened construal of the importance of relationships with others. Individuals in lower socioeconomic status focus more on the external events in their 
lives, which, combined with the value they have for relationships with others, links social class with empathy (Kraus, Cote, \& Keltner, 2010). The gap between socioeconomic classes creates less empathy. Weinger (2000) found that middle class individuals were more likely to feel distant and less likely to have empathy for individuals in a low socioeconomic class.

\section{Video-based Education}

Video-based education is a relatively new form of learning and has many facets that facilitate the dissemination of information to the individual. Narratives can be an important tool to information an individual and can be presented as "a phenomenon that is not limited only to entertainment purposes, but are also widely used for communicating knowledge including factual as well as fictional contents (Glaser, Garsoffky, \& Schwan, 2009). The authors found that narratives can be categorized into dramatization, emotionalization, personalization, and fiction, however these have positive and negative (Glaser et al., 2009). Individuals are receptive when the story's message is set in a social and cultural context that resembles their own (Matthews et al., 2001). McQuiggan, Rowe,

Lee, and Lester (2008) used an interactive narrative-curriculum hybrid game, "Crystal Island," to conduct a study that incorporated 179 eighth grade participants who had recently completed microbiology. The authors found that individuals in the interactive "Crystal Island" narrative showed higher levels of presence which is associated "with factors relevant to learning and motivation, including self-efficacy, interest, involvement/control, and goal orientation” (McQuiggan et al., 2008, p. 8). 
Choi \& Johnson (2007) taught a one-week lesson that used either problem-based video instruction or problem-based text instruction, to 147 students. Participants completed a comprehension quiz on the material as well as a survey on the satisfaction of their instructor, which was then followed by a retention quiz one month after the end of the lesson (Choi \& Johnson, 2007). They found that students had high levels of satisfaction when they were involved in the problem-based video instruction. The authors also found that students showed higher levels of comprehension and retention when exposed to problem-based video instruction. Instructional interactive video in an elearning setting had high levels of satisfaction and higher test scores than groups that were without video or had non-interactive video combined with the lessons (Zhang, Zhou, Briggs, \& Nunamaker jr., 2006).

Observation in a video-based demonstration is also found to be beneficial to individuals (Grierson, Barry, Kapralos, Carnahan, \& Dubrowski, 2012). Grierson, Barry, Kapralos, Carnahan, and Dubrowski (2012) had 26 nursing students watch a simulationbased learning video. The nurses then took a pretest. They then completed a 14-day intervention where they interacted in an educational networking site, took a post-test

followed by a transfer test. Researchers found that the participants greatly benefited from observing correct demonstrations of skills, but they were more successful when they had precise instructions in combination with the observational video. O’Donnell, San Doval, Duran, \& O’Donnell (1995) mirrored the findings of Grierson et al. (2012) by reporting that "the efficacy of video viewing alone was substantially enhanced by using videos as triggers for interactive discussions led by trained facilitators" (p. 820). 
A video-based intervention about sexually transmitted infections was found to significantly increase the use of prophylactics (O’Donnell et al., 1995). Individuals that have had a sexually transmitted infection were less likely to procure prophylactics than individuals who had never had one (O'Donnell et al., 1995). Videos also benefit the individual by improving their self-efficacy (Mathews et al., 2001). Cherrett, Willis, Price, Maynard, and Drior (2009) found these perceived benefits to be beneficial to participants. The study found that interactive video was perceived by $75 \%$ of the participants to enhance their learning experience; however, results indicated that traditional in-class lecture combined with the interactive video is the most effective learning experience (Cherrett et al., 2009). Lents and Cifuentes (2009) found similar results, reporting little difference in exam scores between individuals that watched a standard lecture and a webhybrid video-recorded lecture.

Race may play a role in the ability of the audience member or viewer to respond to a video. Aronson \& Bania (2011) conducted a study using 202 participants who watched videos that promoted HIV tests and prevention. Individuals were asked initially in triage if they wanted an HIV test and then asked again after viewing the video on prevention (Aronson \& Bania, 2011). They found a significant increase in individuals accepting the offer of an HIV test post-viewing of the videos than when in triage; moreover, the authors found that $30 \%$ of participants that had previously declined the HIV test offer accepted it after watching the intervention material. The authors concluded that "a 10-minute protocol can motivate patients to reconsider a decision not to learn their HIV status" (Aronson \& Bania, 2011, p. 101). They also concluded African Americans 
responded more to seeing White individuals on-screen and Whites responded to empathy in the onscreen environment.

\section{Research Questions}

The synthesis of a prosocial behavior such as being an active bystander with the effectiveness of video-based education is the purpose of this thesis. The approach taken will be using the concepts of video-based learning to, at once, teach course content affectively while also giving student the proper tools needed to become an active bystander. This approach supports aspects of previous research as the videos used by the instructors have students critically evaluate them outside of class while concepts from the video regarding course content are being applied to course content inside of the class. The use of video-based learning combined with traditional learning could be a new area of research if it is deemed effective. It is based upon the instructors to assess whether a lesson is effective. This perception of effectiveness regarding the lesson is represented in RQ1 and its subsequent questions:

RQ1: What perceptions do participants have regarding the hybrid lesson plan?

RQ1a: What are the perceived comparative advantages of the hybrid lesson approach as opposed to the present form of lesson used

RQ1b: How well and in what ways does the hybrid lesson translate to the classroom setting?

The second research question is also an important part of this project. The perceptions of the instructors contributes to the validity of the project as they use prior 
knowledge to explore the difference between traditional and hybrid lesson by juxtaposition. This query is represent by research question two:

RQ2: What recommendations, if any, do instructors make regarding the use of the hybrid lesson and/or the videos themselves?

The videos used in this thesis contain aspects that researchers found affective to participants in the literature. The videos consist of college students, who encounter issues such as depression, sexual consent, and alcohol poisoning; all of which are common occurrences on a college campus. The ability to identify with the individuals on-screen as well as the instruction in the classroom becomes the synthetic product of a modified hybrid lesson plan. 


\section{REFERENCES}

Aronson, I. D., \& Bania, T. C. (2011). Race and emotion in computer-based HIV prevention videos for emergency department patients. AIDS Education and Prevention, 23(2), 91-104. doi: 10.1521/aeap.2011.23.2.91

Bailey, P. E., Henry, J. D., \& Von Hippel, W. (2008). Empathy and social functioning in late adulthood. Aging and Mental Health, 12, 499-503.

doi:10.1080/13607860802224243

Banyard, V. L. (2008). Measurement and correlates of prosocial bystander behavior: The case of interpersonal violence. Violence and Victims, 23(1), 83-97. doi: 10.1891/0886-6708.23.1.83

Batson, C. D., Fultz, J., \& Schoenrade, P. A. (1987). Distress and empathy: Two qualitatively distinct vicarious emotions with different motivational consequences. Journal of Personality, 55(1), 19-39. doi: 10.1111/j.14676494.1987.tb00426.x

Bennett, S., Banyard, V., \& Garnhart, L. (2014). To act or not to act, that is the question? Barriers and facilitators of bystander intervention. Journal Of Interpersonal Violence, 29(3), 476-496. doi: 10.1177/0886260513505210

Brauer, M., \& Chekroun, P. (2005). The relationship between perceived violation of social norms and social control: Situational factors influencing the reaction to deviance. Journal of Applied Social Psychology, 35(7), 1519-1539. doi: $10.1111 / \mathrm{j} .1559-1816.2005 . t b 02182 . x$

Carlson, M. (2009) I'd rather go along and be considered a man: Masculinity and bystander intervention. The Journal of Men's Studies, 16(1), 3-17. doi: $10.3149 /$ jms. 1601.3

Chaurand, N., \& Brauer, M. (2008). What determines social control? People's reactions to counternormative behaviors in urban environments. Journal of Applied Social Psychology, 38(7), 1689-1715. doi: 10.1111/j.1559-1816.2008.00365.x

Chekroun, P. \& M. Brauer (2002). The bystander effect and social control behavior: The effect of the presence of others on people's reactions to norm violations. European Journal of Social Psychology, 32(6): 853-867. doi: 10.1002/ejsp.126 
Cherrett, T., Wills, G., Price, J., Maynard, S., \& Dror, I. E. (2009). Making training more cognitively effective: Making videos interactive. British Journal of Educational Technology, 40(6), 1124-1134. doi: 10.1111/j.1467-8535.2009.00985.x

Choi, H. J., \& Johnson, S. D. (2007). The effect of problem-based video instruction on learner satisfaction, comprehension and retention in college courses. British Journal of Educational Technology, 38(5), 885-895. doi: 10.1111/j.14678535.2006.00676.x

Fischer, P., \& Greitemeyer, T. (2013). The positive bystander effect: Passive bystanders increase helping in situations with high expected negative consequences for the helper. The Journal of social psychology, 153(1), 1-5. doi:

10.1080/00224545.2012.697931

Fledderjohann, J., \& Johnson, D. R. (2012). What predicts the actions taken toward observed child neglect? The influence of community context and bystander characteristics. Social Science Quarterly, 93(4), 1030-1052.

doi:10.1111/15406237.2012.00859

Foubert, J. D., \& Rizzo, A. J. (2013). Integrating religiosity and pornography use into the prediction of bystander efficacy and willingness to prevent sexual assault. Journal of Psychology and Theology, 41(3), 242-251. Retrieved from:

http://works.bepress.com/john_foubert/52/

Fredricks, S., Ramsey, M., \& Hornett, A. (2011). Kinship and bystander effect: The role of others in ethical decisions. Journal of Religion and Business Ethics, $2(1), 2$.

Retrieved from: http://via.library.depaul.edu/jrbe/vol2/iss1/2/

Garcia, S. M., Weaver, K., Moskowitz, G. B., \& Darley, J. M. (2002). Crowded minds: The implicit bystander effect. Journal of personality and social psychology, 83(4), 843. doi: 10.1037/0022-3514.83.4.843

Glaser, M., Garsoffky, B., \& Schwan, S. (2009). Narrative-based learning: Possible benefits and problems. Communications, 34(4), 429-447. doi: 10.1515/COMM.2009.026

Grierson, L. E., Barry, M., Kapralos, B., Carnahan, H., \& Dubrowski, A. (2012). The role of collaborative interactivity in the observational practice of clinical skills. Medical education, 46(4), 409-416. doi:10.1111/j.1365-2923.2011.04196.x

Howard, A., Nelson, D., \& Sleigh, M. (2011). Predictors of beliefs about altruism and willingness to behave altruistically. Psi Chi Journal of Undergraduate Research, 16(4). Retrieved from: http://eds.b.ebscohost.com.libproxy.lib.ilstu.edu/eds/pdfviewer/pdfviewer?sid=bf d9b199-9655-4d5a-a14e-9698a992291a\%40sessionmgr111\&vid=2\&hid=116 
Hudson, J. M., \& Bruckman, A. S. (2004). The bystander effect: A lens for understanding patterns of participation. The Journal of the Learning Sciences, 13(2), 165-195. doi: 10.1207/s15327809j1s1302_2

Karniol, R., Gabay, R., Ochion, Y., \& Harari, Y. (1998). Is gender or gender-role orientation a better predictor of empathy in adolescence?. Sex Roles, 39(1-2), 4559. doi: 10.1023/A:1018825732154

Karakashian, L. M., Walter, M. I., Christopher, A. N., \& Lucas, T. (2006). Fear of negative evaluation affects helping behavior: The bystander effect revisited. North American Journal of Psychology, 8(1), 13-32. Retrieved from: http://eds.b.ebscohost.com.libproxy.lib.ilstu.edu/eds/pdfviewer/pdfviewer?sid=bf d9b199-9655-4d5a-a14e-9698a992291a\%40sessionmgr111\&vid=7\&hid=116

Katz, J., Olin, R., Herman, C., \& DuBois, M. (2013). Spotting the signs: First-year college students' responses to bystander-themed rape prevention posters. Journal of Community Psychology, 41(4), 523-529. doi: 10.1002/jcop.21552

Kraus, M. W., Côté, S., \& Keltner, D. (2010). Social class, contextualism, and empathic accuracy. Psychological Science, xx(x), 1-8. doi: 10.1177/0956797610387613

Latane, B., \& Rodin, J. (1969). A lady in distress: Inhibiting effects of friends and strangers on bystander intervention. Journal of Experimental Social Psychology, 5(2), 189-202. doi: 10.1016/0022-1031(69)90046-8

Lents, N. H., \& Cifuentes, O. E. (2009). Web-based learning enhancements: Video lectures through voice-over powerpoint in a majors-level biology course. Journal of College Science Teaching, 39(2), 38-46.Retrieved from:

http://eric.ed.gov/?id=EJ862192

Levine, M., Prosser, A., Evans, D., \& Reicher, S. (2005). Identity and emergency intervention: How social group membership and inclusiveness of group boundaries shape helping behavior. Personality and Social Psychology Bulletin, 31(4), 443-453. doi: 10.1177/0146167204271651

Macháčková, H., Dedkova, L., Sevcikova, A., \& Cerna, A. (2013). Bystanders' support of cyberbullied schoolmates. Journal of Community \& Applied Social Psychology, 23(1), 25-36. doi: 10.1002/casp.2135

Manning, R., Levine, M., \& Collins, A. (2007). The Kitty Genovese murder and the social psychology of helping: The parable of the 38 witnesses. American Psychologist, 62(6), 555. doi: 10.1037/0003-066X.62.6.555

Marsh, A. A., Kozak, M. N., \& Ambady, N. (2007). Accurate identification of fear facial expressions predicts prosocial behavior. Emotion, 7(2), 239. doi: 10.1037/15283542.7.2.239 
Mathews, C., Guttmacher, S. J., Coetzee, N., Magwaza, S., Stein, J., Lombard, C., \& Coetzee, D. (2002). Evaluation of a video based health education strategy to improve sexually transmitted disease partner notification in South Africa. Sexually Transmitted Infections, 78(1), 53-57. doi:10.1136/sti.78.1.53

Nwankwo, B. E. (2013). Role of gender, emotional empathy, interpersonal attraction on moral judgement. Ife PsychologIA, 21(2). Retrieved from: http://eds.a.ebscohost.com/ehost/detail?sid=7e76b7a3-7a8d-4d9d-8729bc7c43cb5235\%40sessionmgr4003\&vid=1\&hid=4110\&bdata=JnNpdGU9ZWhvc 3QtbG12ZSZzY29wZT1zaXRl\#db=a9h\&AN=90257406

O'Donnell, L. N., Doval, A. S., Duran, R., \& O'Donnell, C. (1995). Video-based sexually transmitted disease patient education: its impact on condom acquisition. American Journal of Public Health, 85(6), 817-822. doi: 10.2105/AJPH.85.6.817

Piff, P. K., Kraus, M. W., Côté, S., Cheng, B. H., \& Keltner, D. (2010). Having less, giving more: The influence of social class on prosocial behavior. Journal of Personality and Social Psychology, 99(5), 771-784. doi: 10.1037/a0020092

Preston, S. D., \& De Waal, F. (2002). Empathy: Its ultimate and proximate bases. Behavioral and Brain Sciences, 25(01), 1-20. Retrieved from: http://dx.doi.org/10.1017/S0140525X02000018

Scully, M., \& Rowe, M. (2009). Bystander training within organizations. Journal of the International Ombudsman Association, 2(1), 1-7. Retrieved from:

http://eds.b.ebscohost.com.libproxy.lib.ilstu.edu/eds/detail/detail?vid=9\&sid=bfd9 b199-9655-4d5a-a14e 9698a992291a\%40sessionmgr111\&hid=116\&bdata=JnNpdGU9ZWRzLWxpdm Umc2NvcGU9c210ZQ\%3d\%3d\#db=a9h\&AN=52423873

Shen, L. (2011). The effectiveness of empathy-versus fear-arousing antismoking PSAs. Health Communication, 26(5), 404-415. doi: 10.1080/10410236.2011.552480

Thornberg, R. (2007). A classmate in distress: Schoolchildren as bystanders and their reasons for how they act. Social Psychology of Education, 10(1), 5-28. doi: $10.1007 / 1121800690094$

Turner, R. H. (1969). The public perception of protest. American Sociological Review, 34(6), 815-831. Retrieved from: http://scholar.google.com/scholar?q=The+public + perception + of + protest\&btnG $=$ $\& \mathrm{hl}=$ en\&as_sdt $=0 \% 2 \mathrm{C} 14$

Weinger, S. (2000). Economic status: Middle class and poor children's views. Children \& Society, 14(2), 135-146. doi: 10.1111/j.1099-0860.2000.tb00161.x 
Wood, J. L., James, M., \& Ciardha, C. Ó. (2014). 'I know how they must feel': Empathy and judging defendants. The European Journal of Psychology Applied to Legal Context, 6(1), 37-43. Retrieved from:

http://www.sciencedirect.com/science/article/pii/S1889186114700101

Xu, H., Kou, Y., \& Zhong, N. (2012). The effect of empathy on cooperation, forgiveness, and "returning good for evil" in the prisoner's dilemma. Public Personnel Management, 41(5), 105-115. doi: 10.1177/009102601204100510

Zhang, D., Zhou, L., Briggs, R. O., \& Nunamaker Jr, J. F. (2006). Instructional video in e-learning: Assessing the impact of interactive video on learning effectiveness.

Information \& Management, 43(1), 15-27. doi:10.1016/j.im.2005.01.004 


\section{APPENDIX}

\section{HYBRID LESSON PLAN USED BY PARTICIPANTS}




\title{
The Importance of Becoming an Active Bystander
}

\author{
Chris Noel
}

\begin{tabular}{|l|l|}
\hline Grade Level(s) & University Level \\
\hline Topic & The Bystander Effect \\
\hline Information Addressed & $\begin{array}{l}\text { Intervention techniques and identification of the bystander effect, which } \\
\text { also integrates previous course concepts. }\end{array}$ \\
\hline Key Terms & $\begin{array}{l}\text { Behavior, Bystander, Groupthink, Citizenship, Decision-Making, } \\
\text { Perception }\end{array}$ \\
\hline Supstract & $\begin{array}{l}\text { Chalk Board or Dry Erase Board } \\
\text { Dry Erase Marker or Chalk }\end{array}$ \\
\hline $\begin{array}{l}\text { Groups can be powerful entities, be it for good or bad. In these groups } \\
\text { individuals have roles, however, there are instances when said roles inhibit } \\
\text { action. This is known as the bystander effect, when you become a passive } \\
\text { member of a situation where another is in distress. This lesson plan seeks } \\
\text { to give students the skills to become prosocial, active bystanders as well } \\
\text { as reinforcing ideologies of the bystander effect in group think. This will be } \\
\text { a two-step lesson plan. The first portion will consist of a brief overview of } \\
\text { the bystander effect and its origins. Three videos and a 15 minute } \\
\text { PowerPoint video will be assigned, which delineate information and } \\
\text { scenarios dealing with the bystander effect and elements of groupthink, } \\
\text { citizenship, decision-making, and perception. Students will be asked to fill } \\
\text { out three separate sheets asking questions about the scenario they } \\
\text { viewed. The second portion of the lesson extrapolates on concepts of the } \\
\text { video which pertain to the bystander effect as well as the concepts } \\
\text { mentioned above. The lesson concludes by synthesizing the concepts } \\
\text { learned }\end{array}$ \\
\hline
\end{tabular}

I. Introduction

A. Take a moment to think about the last time you experienced a situation where you knew someone was in distress and did not intervene. How did this make you feel?

B. In this chapter we have learned about elements of groups. Think of some elements that are positive and negative about groups (Positive: problem solving, Negative: groupthink, interdependence.)

C. At the end of this lesson you will understand the power of groups and the ways they positively and negatively affect our lives. 


\section{The Lesson (Experience)}

A. An Introduction to The Bystander Effect (Day 1)

1. Who can tell me a bit about the bystander effect? (The bystander effect occurs when an individual or individuals do not act in a situation where another individual or individuals is in distress because they believe someone else will intervene, which causes they to relinquish responsibility.)

a. (Give a few moments) Excellent!

2. The bystander effect was first introduced in 1964 when 38 individuals witnessed Kitty Genovese being murdered. None of the individuals chose to help Genovese even though they saw the attack. Eventually, someone did call the police.

a. Why do you believe no one helped her?

- (Give Time for reasons) Okay, great! Now, I would like you to step into the frame of mind of a bystander for our next class.

3. For next time, I would like you to watch a brief PowerPoint video about the bystander effect as well as watch three scenarios. Each scenario has four questions that you will answer and bring them with you to class where we will discuss them a bit more in-depth.

B. Scenario Evaluation and Discussion (Day 2)

1. In the "Withdrawn Friend" scenario, what were some elements that Marcus and Josh saw in Alex that caused them to be worried?

a. (He regularly passed them by and stopped hanging out with them in previously enjoyed activities.)

b. We learned in chapter 1 about being citizenship, which enables us to gain skills to speak out for the greater good. How did Marcus and Josh exemplify their citizenship? (They came together and decided to tell him how and where to get help.)

2. Okay, in scenario 2 we see what happens when alcohol becomes a factor in our decisions. Remember in chapter 4 we learned that perception is the process by which we select, organize, and interpret the world around us. What was the general perception regarding consent while intoxicated?

a. What are the differences between each couple? (Josh- he was intoxicated just as much as the woman. While it was more acceptable than Arthur's portion, intoxicated individuals are NOT able to give consent. Arthur's version was more coercive.)

b. In chapter 17 we will learn how perception influences our decisionmaking. Using what you know now about consent, what different decisions could they have made?

3. In the final scenario, we are at the same party later on and we see that one individual has become increasingly intoxicated. What would have been some preventative measures those individuals at the party should have taken prior to Marie's incident? (Ex: asked her to slow down, have others take notice of her drinking, kept an eye on her, etc.)

a. In this chapter we learned about groupthink. What is groupthink? (A process that occurs when members of the group are more concerned with getting the task done as opposed to getting it done right.)

b. How does Marcus avoid groupthink? (He does not listen when he is being told to let her sleep so that they can all go to "Cherrystock", He decides to call 911 , He kicks the others out.) 
c. How would you have reacted if you were in the same situation as Marcus? (Allow a few minutes to come up with some examples.)

d. Great, now, according to the introduction video and the scenario, how is it that Marcus was protected by student law when reporting the incident?

\section{Conclusion (Debrief)}

A. What did we learn about the bystander effect? (It inhibits action in helping others.) What did we learn about strategies to become an active bystander by doing prosocial actions? (We must implicate and identify with individuals so that we may take action.) Why is it important to understand how groupthink, citizenship, perception, and decision-making affect the way we engage with others? (So that we are able to be a contributing member of the social world.)

B. We discovered that the bystander effect can happen all around us. We also learned how to identify certain situations so that we are better able to react in the situation and become an active bystander to help the individual in distress. Using course concepts such as decision-making, perception, groupthink, and citizenship, we learned that engaging with others is a process and we must be well-informed in order to navigate the situation. Through watching and critically evaluating the videos, we gathered techniques that can be used in specific situations when someone is in distress and that not every situation is similar. We must react in ways that are beneficial to the individual. We also learned how we can get help and tips at Student Counseling Services.

C. How can you apply what you have learned today? At school? At home? With your friends? You now have some of the tools that will help you make safe decisions that will positively impact your life.

\section{Other materials that teach this concept:}

See the PowerPoint video used in this lesson for a more in-depth explanation of the bystander effect. 
Please answer the following questions to the best of your ability regarding the video titled, "The Withdrawn Friend."

1. What behaviors were being exhibited by Alex, the withdrawn friend?

2. What was the compromise that Marcus and Josh came up with?

3. What were the techniques they used to intervene?

4. How would you have intervened? 
Please answer the following questions to the best of your ability regarding the video titled, "Consent."

1. Is consent able to be given when intoxicated? Why or Why not?

2. Do you believe their decision-making abilities were impaired?

3. What were some differences between Josh and the woman in the hall and Arthur and the woman on the couch?

4. After having watched the video, what are some strategies you would have used to intervene? 
Please answer the following questions to the best of your ability regarding the video titled, "The Party Is Over."

1. What were some signs that Marie's friends did not see as she gradually became more and more intoxicated?

2. What did Marcus notice about Marie that caused him to act?

3. What was Marcus's strategy to help his friend?

4. What strategies would you have used to help Marie? 